\title{
Simultaneous spectrofluorometric analysis of tablets containing hydrochlorothiazide combined with timolol maleate or amiloride hydrochloride
}

FADEL WEDIAN ${ }^{1, *}$

ANAS LATAIFEH ${ }^{2}$

MAKASEB S. MOHAMMED ${ }^{1}$

${ }^{1}$ Department of Chemistry

Faculty of Science, Yarmouk University

P.O. Box 560, Irbid 22163, Jordan

${ }^{2}$ Department of Chemistry

Faculty of Science, Tafila Technical

University, Tafila 66110, Jordan
Accepted September 30, 2019

Published online November 4, 2019

\begin{abstract}
Green and sensitive spectrofluorometric methods have been developed and validated for the determination of timolol maleate (TML)/hydrochlorothiazide (HCT) and amiloride hydrochloride (AMH)/hydrochlorothiazide in tablets. The proposed spectrofluorometric procedures were found to be linear in the range of 4-12, 5-35 and 0.025-0.2 $\mathrm{mg} \mathrm{L}^{-1}$ for HCT, TML and AMH, resp. The excitation and emission wavelengths for HCT, TML and AMH at room temperature were 270 and 375, 295 and 435, 330 and $415 \mathrm{~nm}$, resp. The methods were validated with respect to $\mathrm{ICH}$ guidelines. The AMH showed higher sensitivity with lower values of $L O D$ and $L O Q$ values compared to HCT and TML. The proposed methods were applied to two pharmaceutical formulations; the method for HCT and AMH has proven as reliable assaying method, whereas the method for TML, when combined with HCT, is applicable to screening semiquantitative analyses.
\end{abstract}

Keywords: hydrochlorothiazide, amiloride hydrochloride, timolol maleate, fixed-dose combinations, spectrofluorometry, assaying, screening

Moduretic (Uniretic) and Timolide are examples of fixed-dose drug combinations that contain beta-adrenergic blocking agents and hydrochlorothiazide (HCT) as a second active component. Moduretic contains amiloride hydrochloride (AMH) with HCT. AMH is $\mathrm{N}$-amidino-3,5-diamino-6-chloropyrazine-2-carboxamide hydrochloride, which has an empirical formula $\mathrm{C}_{6} \mathrm{H}_{9} \mathrm{Cl}_{2} \mathrm{~N}_{7} \mathrm{O}$. It is a potassium preserving diuretic with antihypertensive activity. It is employed as additional treatment with thiazide diuretics to aid in the restoration of normal serum potassium levels and to prevent the development of hypokalemia (1). HCT is 6-chloro-3,4-dihydro-2H-1,2,4-benzothiadiazine-7-sulfonamide-1,1-dioxide. Its empirical formula is $\mathrm{C}_{7} \mathrm{H}_{8} \mathrm{ClN}_{3} \mathrm{O}_{4} \mathrm{~S}_{2}$. The HCT is a diuretic agent, which is used in the treatment of oedema associated with congestive heart failure and renal and hepatic disorders $(2,3)$.

\footnotetext{
*Correspondence, e-mail: alwedian@yu.edu.jo
} 
Timolide is supplied as tablets containing timolol maleate (TML) and HCT. TML is (2S)-1-[(1,1-dimethyl-ethyl)amino]-3-[[4-(morpholin-4-yl)-1,2,5-thiadiazol-3-yl] oxy] propan-2-ol (Z)-butenedioate. It has a molecular formula $\mathrm{C}_{13} \mathrm{H}_{24} \mathrm{~N}_{4} \mathrm{O}_{3} \mathrm{~S} \times \mathrm{C}_{4} \mathrm{H}_{4} \mathrm{O}_{4}$ with a molar mass of 432.49. TML is a non-cardioselective beta-blocker; it is widely used as standard medication for intraocular pressure (glaucoma) by preventing the production of aqueous humor. It is also an active treatment for hypertension, angina pectoris and myocardial infarction (3-5).

In recent years, increasing attention has been focused on the simultaneous determination of binary mixture of AMH/HCT. Sophisticated instrumentation and techniques were applied for the quantitative analysis. Availability of apparatus, high-cost organic solvents and high cost of such analyses limited their routine use. Some of these techniques are spectrophotometric absorbance ratio method (6), ratio spectra derivative spectrophotometry coupled HPLC $(7,8)$, differential pulse polarography coupled with partial least squares (9), and the reversed-phase HPLC method (10-12).

Few analytical techniques have been reported for the analysis of HCT and TML combinations, for example, derivative and derivative-ratio spectrophotometry (8) and the flowinjection method (13).

Analysis of AMH and HCT combinations and, even more, in the combination with TML or another component was reported $(6,7)$. Chemometric procedures such as classical least squares (CLS), principal components regression (PCR) and partial least squares were successfully applied for the analysis of synthetic samples and commercial tablet preparations containing $\mathrm{AMH}$ and $\mathrm{HCT}$ alone, or containing $\mathrm{AMH}, \mathrm{HCT}$ in association with atenolol (ATL) or TML (6). Moreover, analysis of combinations of three components, $\mathrm{AMH}, \mathrm{HCT}$ and ATL in combined formulations was carried out using derivative spectroscopy (7).

This work was intended to demonstrate the analysis of the aforementioned analytes in combined formulations in the aqueous medium, to meet the requirements of green chemistry (14). It was devoted to the application and development of spectrofluorometric method for the analysis of $\mathrm{AMH} / \mathrm{HCT}$ and TML/HCT in synthetic samples and marketed formulations.

\section{EXPERIMENTAL}

\section{Apparatus}

Perkin Elmer LS45 Fluorescence Spectrometer was used for fluorescence measurements using a 1-cm quartz cuvette, part number B0631107 (Perkin Elmer, USA). The data analyses were carried out using a Flwinlab software, version 4.00.03. All measurements were carried out at $22 \pm 2{ }^{\circ} \mathrm{C}$.

\section{Materials}

The HCT (purity $99.2 \%$ ) was purchased from Unichem Laboratories Limited, India. AMH was supplied by Bal Pharma Limited, India (purity $99 \%$ ). TML was supplied by Supriya Lifescience Ltd., India (purity 99 \%). Magnesium stearate (Sigma-Aldrich, USA), 
povidone (VWR, USA), lactose (VWR), corn starch (Avonchem Limited, UK), colloidal silicon dioxide (Sigma-Aldrich), cellulose (Fisher Scientific SAS, France), Insacoat II IA30103 colorant (United Pharmaceuticals, Jordan), FD\&C Blue 2 colorant (Hikma Pharmaceuticals, Jordan) were used to prepare placebo powder.

Commercial tablets Uniretic ${ }^{\circledR}$ - amiloride hydrochloride $(5 \mathrm{mg})$ and hydrochlorothiazide (50 mg) (United Pharmaceuticals, Jordan) and Timolide ${ }^{\circledR}$ - timolol maleate (10 mg) and hydrochlorothiazide (25 mg) (Merck Inc., USA), were analyzed. The Uniretic excipients provided by the manufacturer were: povidone, lactose, corn starch, colloidal silicon dioxide, Insacoat II IA-30103 colorant and magnesium stearate. Timolide ${ }^{\circledR}$ excipients were cellulose, starch, magnesium stearate and FD\&C Blue 2 colorant.

\section{Standard solutions}

Standard stock solutions. - HCT, AMH, and TML stock solutions were prepared from $100 \mathrm{mg}$ of pure powder of each compound, accurately weighed, and transferred into a 500$\mathrm{mL}$ volumetric flask containing $1.0 \mathrm{~mL}$ ethanol. The solution was shaken well and thereafter diluted to the mark with distilled water. The stock solutions (200 $\left.\mathrm{mg} \mathrm{L}^{-1}\right)$ were protected from light and kept at room temperature.

\section{Validation of spectrofluorometric methods}

Validation of the analytical methods was performed with respect to linearity, the limit of detection and quantitation, accuracy and precision, specificity and robustness, according to the ICH guidelines (15).

Linearity. - It was evaluated by analyzing five-level standard solutions for $\mathrm{HCH}, \mathrm{AMH}$, and TML in triplicate. Under the best experimental conditions, linear relationships between fluorescence intensity and concentration were achieved.

Limits of detection and quantitation (LODELOQ). - LOD is defined as 3.3 $\sigma / s$, where $\sigma$ is the standard deviation of replicate determinations of a blank, $s$ is the slope of the regression line, while $L O Q$ is defined as $10 \sigma / s$.

Accuracy and precision. - The model accuracy was evaluated by applying the proposed methods to the determination of three different concentrations of HCT (5, 7 and $11 \mathrm{mg}$ $\left.\mathrm{L}^{-1}\right), \mathrm{AMH}$ (0.030, 0.12 and $0.18 \mathrm{mg} \mathrm{L}^{-1}$ ) and TML (6, 16 and $24 \mathrm{mg} \mathrm{L}^{-1}$ ) (5 replicates). The determination of standard HCT, AMH and TML were carried out on the same day and for three consecutive days to test the repeatability and intermediate precision of the proposed methods.

Specificity. - It was achieved with the analysis of ten synthetic mixtures of HCT/AMH and HCT/TML. The ratios of the training set mixtures were selected randomly with two mixtures (mixture 3: 10:1, m/m, HCT/AMH, and mixture 9:2:1, m/m, HCT/TML) reproducing the composition of the commercial tablets (Uniretic ${ }^{\circledR}$ and Timolide ${ }^{\circledR}$ ). To ensure that these mixtures are mimicking the real samples, the prepared solutions were mixed with placebo powder ( $1 \mathrm{~mL}$ in $0.1 \mathrm{~g}$ powder), vortexed, stored for 10 minutes at $4{ }^{\circ} \mathrm{C}$ and then filtered (0.2- $\mu \mathrm{m}$ pore size). 
Emission spectra of HCT, AMH, and TML were partially overlapping in the region between 350 and $480 \mathrm{~nm}$. A background subtraction approach was utilized to resolve this overlapping. This approach was applied to extract fluorescence spectra from Raman fluorescence in the case when the samples exhibited both fluorescence and Raman $(16,17)$.

In this case, it is necessary to neglect the effect of the internal absorption of one compound from the emission of the second compound. In the analysis of mixture 1 that contained HCT and $\mathrm{AMH}$, emission of $\mathrm{AMH}$ was considered as background for the emission spectra of HCT/AMH solution. To fulfill such consideration, the fluorescence spectrum for $\mathrm{AMH}$ with concentration exactly equal to that in the mixture was recorded and stored as a background. The background subtraction facility in the software was used to extract the fluorescence of HCT from the emission of the mixture. A similar approach was used to evaluate the concentration of $\mathrm{AMH}$ in the mixture solution.

Robustness. - It was evaluated by studying the influence of small variations of the method conditions. These parameters include a variation of the excitation wavelength by $\pm 2 \mathrm{~nm}$, the solution temperature by $\pm 5{ }^{\circ} \mathrm{C}$, and emission wavelength by $\pm 2 \mathrm{~nm}$. Three concentrations $\left(5,7,11 \mathrm{mg} \mathrm{L}^{-1}\right)$ of standard HCT, $\left(0.030,0.12,0.18 \mathrm{mg} \mathrm{L}^{-1}\right)$ of standard AMH, and $\left(6,16,24 \mathrm{mg} \mathrm{L}^{-1}\right)$ of standard TML were analyzed and evaluated, and one parameter was changed at a time.

\section{Commercial tablets analysis}

Stock and working solutions of market samples were prepared by pounding 20 tablets of each formulation to a powder. An accurately weighed amount (1.8843 g) of Uniretic ${ }^{\circledR}$ was

Table I. Analytical parameters for proposed spectrofluorometric methods

\begin{tabular}{|c|c|c|c|}
\hline Parameter & HCT & $\mathrm{AMH}$ & TML \\
\hline$\lambda_{\mathrm{ex}}(\mathrm{nm})$ & 270 & 330 & 295 \\
\hline$\lambda_{\mathrm{em}}(\mathrm{nm})$ & 375 & 415 & 435 \\
\hline Linearity range $\left(\mathrm{mg} \mathrm{L}^{-1}\right)$ & $4.0-12.0$ & $0.025-0.20$ & $5.0-35.0$ \\
\hline \multicolumn{4}{|l|}{ Regression parameters ${ }^{a}$} \\
\hline Slope (s) & 2.264 & 3841.04 & 5.610 \\
\hline Standard deviation of slope $\left(S_{\mathrm{s}}\right)$ & 0.255 & 65.112 & 0.240 \\
\hline Intercept $(b)$ & 58.575 & 14.425 & 5.333 \\
\hline Standard deviation of intercept $\left(S_{\mathrm{b}}\right)$ & 1.877 & 8.916 & 3.693 \\
\hline Correlation coefficient $(R)$ & 0.987 & 0.999 & 0.996 \\
\hline Residual standard deviation $\left(S_{x / y}\right)$ & 1.143 & 7.277 & 2.008 \\
\hline $\operatorname{LOD}\left(\mathrm{mg} \mathrm{L}^{-1}\right)^{\mathrm{b}}$ & 0.0104 & 0.0013 & 0.070 \\
\hline $\operatorname{LOQ}\left(\mathrm{mg} \mathrm{L}^{-1}\right)^{\mathrm{b}}$ & 0.312 & 0.0040 & 0.210 \\
\hline
\end{tabular}

${ }^{a} Y=s g+b, g$ is a concentration in $\mathrm{mg} \mathrm{L}^{-1}$ and $Y$ is fluorescence intensity.

${ }^{\mathrm{b}} L O D$ and $L O Q$ were calculated as following: $L O D=3.3 \sigma / \mathrm{s}$ and $L O Q=10 \sigma / \mathrm{s}$, where $\sigma$ is the standard deviation of replicate determinations of blank, $s$ is the slope of the regression line. 


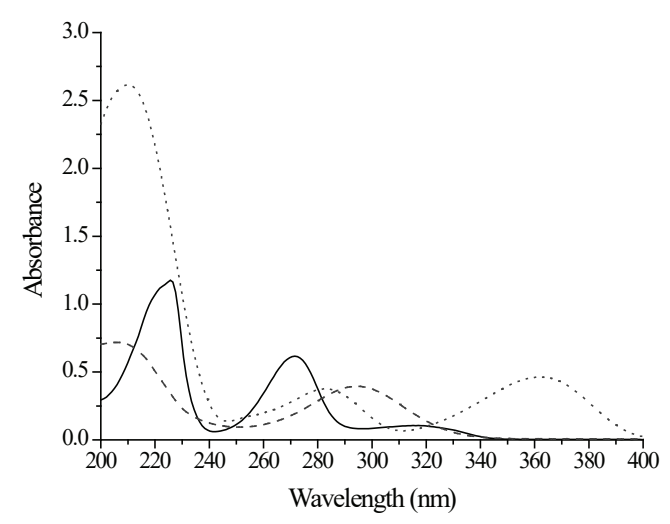

Fig. 1. Absorption spectra of $10 \mathrm{mg} \mathrm{L}^{-1} \mathrm{HCT}$ against EtOH/ $\mathrm{H}_{2} \mathrm{O}$ (solid line), $8 \mathrm{mg} \mathrm{L}^{-1} \mathrm{AMH}$ against $\mathrm{H}_{2} \mathrm{O}$ (dot line) and $20 \mathrm{mg} \mathrm{L}^{-1} \mathrm{TML}$ against $\mathrm{H}_{2} \mathrm{O}$ (dash line).

transferred into a $250-\mathrm{mL}$ volumetric flask containing $10 \%$ aqueous ethanol. The solution was then sonicated for a few minutes and filtered using a $0.20-\mu \mathrm{m}$ Whatman filter paper to remove insoluble components to get $215 \mathrm{mg} \mathrm{L}^{-1} \mathrm{HCT}$ and $1076 \mathrm{mg} \mathrm{L}^{-1} \mathrm{AMH}$ (as stock). An appropriate aliquot $(0.60 \mathrm{~mL})$ from the stock was transferred to a $25-\mathrm{mL}$ volumetric flask to prepare $5.2 \mathrm{mg} \mathrm{L}^{-1} \mathrm{HCT}$ and $25.8 \mathrm{mg} \mathrm{L}^{-1} \mathrm{AMH}$.

The stock and working solutions of Timolide ${ }^{\circledR}$ were prepared as previously described for Uniretic ${ }^{\circledR}$. The stock solution was prepared by dissolving $0.4233 \mathrm{~g}$ of Timolide ${ }^{\circledR}$ powder in water. HCT and TMT were $10.8 \mathrm{mg} \mathrm{L}^{-1}$ and $24.7 \mathrm{mg} \mathrm{L}^{-1}$, resp., in water, after dilution.

The concentration of HCT, AMH and TMT in laboratory prepared mixtures and commercial preparations were calculated using the parameters of the linear regression of each combination (Table I).

\section{RESULTS AND DISCUSSION}

\section{Absorption and fluorescence spectra}

Spectra of HCT, TML and AMH were separately recorded using water as a blank (see Fig. 1). Fig. 1 shows that absorption peaks of HCT were at 225, 270 and $316 \mathrm{~nm}$ with molar absorptivity of $3.45 \times 10^{4}, 1.78 \times 10^{4}$ and $2.91 \times 10^{3} \mathrm{~L} \mathrm{~mol}^{-1} \mathrm{~cm}^{-1}$, resp., of TML at 207 and 295 nm with molar absorptivity of $1.56 \times 10^{4}$ and $8.58 \times 10^{3} \mathrm{~L} \mathrm{~mol}^{-1} \mathrm{~cm}^{-1}$, resp., and of AMH at 210, 285 and $365 \mathrm{~nm}$ with molar absorptivity of $8.80 \times 10^{4}, 1.26 \times 10^{4}$ and $1.55 \times 10^{4} \mathrm{~L} \mathrm{~mol}^{-1}$ $\mathrm{cm}^{-1}$, resp.

The quantitative analyses of HCT, TML and AMH in artificial mixtures and binary pharmaceutical formulations as HCT/TML and HCT/AMH were based on the direct measurements of their fluorescence. HCT, TML and AMH exhibited maximum fluorescence at $\lambda_{\mathrm{em}}$ of $375 \mathrm{~nm}$ for HCT, $435 \mathrm{~nm}$ for TML and $415 \mathrm{~nm}$ for AMH after excitation at $\lambda_{\mathrm{ex}}$ of 270, 295 and $330 \mathrm{~nm}$ for HCT, TML and AMH, resp. (see Fig. 2). The fluorescence of these compounds was greatly influenced by drug excipients which decreased the compounds' quantum 


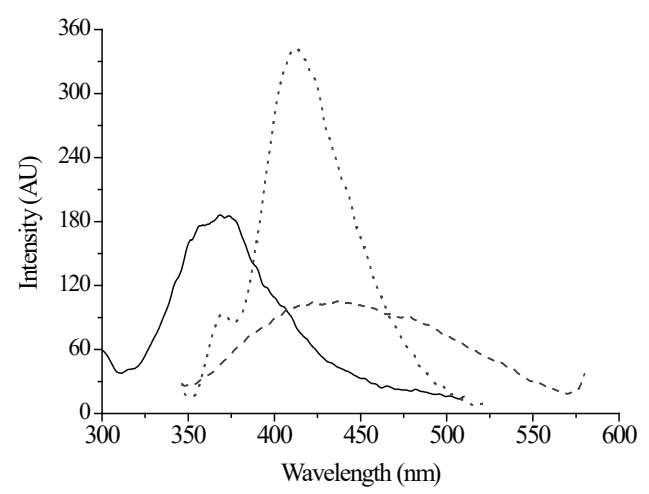

Fig. 2. Fluorescence spectra of $12.0 \mathrm{mg} \mathrm{L}^{-1} \mathrm{HCT}$ using $\lambda_{\mathrm{ex}}=270 \mathrm{~nm}$ (solid line), $0.20 \mathrm{mg} \mathrm{L}^{-1} \mathrm{AMH}$ using $\lambda_{\mathrm{ex}}=330 \mathrm{~nm}$ (dot line), $20.0 \mathrm{mg} \mathrm{L}^{-1}$ TML using $\lambda_{\mathrm{ex}}=295 \mathrm{~nm}$ (dash line).

yields (increased rates of radiationless decay) resulting in low sensitivity of detection. To minimize the influence of common excipients on fluorescence intensities of target compounds, filtration and spectral data manipulation were carried out.

\section{Validation of the spectrofluorometric methods}

Linearity. - Under the best experimental conditions of dilution and concentrations, linear relationships were established in the range of 4-12 $\mathrm{mg} \mathrm{L}^{-1}$ for HCT, $0.025-0.20 \mathrm{mg}$ $\mathrm{L}^{-1} \mathrm{AMH}$ and $5-35 \mathrm{mg} \mathrm{L}^{-1} \mathrm{TML}$. The respective regression equations for $\mathrm{HCT}, \mathrm{AMH}$ and TML and their parameters such as slope (a) and standard deviation of the slope $\left(S_{\mathrm{a}}\right)$, intercept (b) and standard deviation of the intercept $\left(S_{\mathrm{b}}\right)$, and residual standard deviation $\left(S_{\mathrm{x} / \mathrm{y}}\right)$ were calculated (see Table I).

Limits of detection and quantitation. - The calculated limits of detection for HCT, AMH, and TML were $0.0104,0.0013$ and $0.070 \mathrm{mg} \mathrm{L}^{-1}$, resp. (Table I).

Accuracy and precision. - The model average percent recoveries ranged 99.9-100.4, 99.4100.3 and $99.0-100.3 \%$ for HCT, AMH and TML, resp. The observed bias in the accuracy was acceptable since it was within the margin of errors. Thus, an adequate accuracy of the model was achieved. The precision of the method was judged by performing intra-day and inter-day analysis. The repeatability RSD was $0.6,0.4$ and $0.6 \%$ for HCT, AMH and TML, resp. The intermediate precisions RSD was $0.7,0.7$ and $0.8 \%$ for HCT, AMH and TML, resp. The RSDs below $1 \%$ indicated reasonable repeatability and intermediate precision. The results are summarized in Table II.

Specificity. - The specificity of the developed method was performed on HCT/AMH and HCT/TML combinations in synthetic mixtures with added excipients, simulating the composition of drug formulations Uniretic ${ }^{\circledR}$ and Timolide ${ }^{\circledR}$. The emission spectra of synthetic mixtures displayed in Table III are presented in Figs. 3 and 4. Since emission spectra of HCT, AMH, and TML were partially overlapping in the region between 350 and $480 \mathrm{~nm}$, background subtraction approach was utilized. For example, in the analysis of mixture 1 which contained HCT and AMH (see Table III), emission of AMH or HCT was set as a 
F. Wedian et al.: Simultaneous spectrofluorometric analysis of tablets containing hydrochlorothiazide combined with timolol maleate or amiloride hydrochloride, Acta Pharm. 70 (2020) 373-385.

Table II. Model accuracy and precision of the proposed spectrofluorometric methods for determination of $H C T, A M H$ and $T M L$

\begin{tabular}{ccccc}
\hline \multirow{2}{*}{ Analyte } & $\begin{array}{c}\text { Concentration } \\
\left(\mathrm{mg} \mathrm{L}^{-1}\right)\end{array}$ & Recovery & \multicolumn{2}{c}{ RSD $(\%)$} \\
\cline { 3 - 5 } & 5 & $(\%)^{\mathrm{a}}$ & Intra-day & Inter-day \\
\hline \multirow{3}{*}{ HCT } & 7 & 99.6 & 0.6 & 0.5 \\
& 11 & 98.8 & 0.7 & 0.7 \\
& 0.030 & 100.4 & 0.5 & 0.9 \\
AMH & 0.12 & 99.4 & 0.5 & 0.9 \\
& 0.18 & 100.1 & 0.4 & 0.7 \\
& 6 & 100.3 & 0.4 & 0.6 \\
TML & 16 & 99.0 & 0.6 & 0.7 \\
& 24 & 99.5 & 0.6 & 0.8 \\
\hline
\end{tabular}

${ }^{a}$ Mean of five determinations.

Table III. Application of spectrofluorometric methods for the determination of HTC/AMH and HCT/TML in synthetic mixtures

\begin{tabular}{|c|c|c|c|c|c|c|}
\hline Mixture & $\begin{array}{l}\text { Actual } \\
\left(\mathrm{mg} \mathrm{L}^{-1}\right)\end{array}$ & $\begin{array}{l}\text { Found } \\
\left(\mathrm{mg} \mathrm{L}^{-1}\right)^{\mathrm{a}}\end{array}$ & $\begin{array}{c}\text { Recovery } \\
(\%)\end{array}$ & $\begin{array}{l}\text { Actual } \\
\left(\mathrm{mg} \mathrm{L}^{-1}\right)\end{array}$ & $\begin{array}{l}\text { Found } \\
\left(\mathrm{mg} \mathrm{L}^{-1}\right)^{\mathrm{a}}\end{array}$ & $\begin{array}{c}\text { Recovery } \\
(\%)\end{array}$ \\
\hline \multicolumn{4}{|c|}{ HCT } & \multicolumn{3}{|c|}{$\mathrm{AMH}$} \\
\hline $1(4: 1)$ & 3.20 & 3.16 & 98.5 & 0.80 & 0.78 & 98.8 \\
\hline $2(8: 1)$ & 6.40 & 6.30 & 97.4 & 0.80 & 0.79 & 98.8 \\
\hline $3(10: 1)^{b}$ & 8.00 & 7.92 & 99.0 & 0.80 & 0.78 & 97.5 \\
\hline $4(15: 1)$ & 12.0 & 11.4 & 96.4 & 0.80 & 0.77 & 96.3 \\
\hline $5(20: 1)$ & 16.0 & 15.4 & 96.3 & 0.80 & 0.76 & 95.0 \\
\hline Mean \pm SD & & & $97.5 \pm 1.2$ & & & $97.3 \pm 0.6$ \\
\hline \multicolumn{4}{|c|}{ HCT } & \multicolumn{3}{|c|}{ TML } \\
\hline $6(1: 1)$ & 10.0 & 9.90 & 98.6 & 10.0 & 9.69 & 96.8 \\
\hline $7(1: 2)$ & 10.0 & 9.94 & 99.3 & 20.0 & 19.5 & 97.5 \\
\hline $8(1: 3)$ & 10.0 & 9.67 & 96.6 & 30.0 & 28.7 & 95.6 \\
\hline $9(2: 1)^{c}$ & 20.0 & 19.5 & 97.2 & 10.0 & 9.72 & 97.1 \\
\hline $10(3: 1)$ & 30.0 & 29.2 & 97.3 & 10.0 & 9.85 & 98.6 \\
\hline Mean \pm SD & & & $97.8 \pm 1.1$ & & & $97.1 \pm 1.0$ \\
\hline
\end{tabular}

${ }^{a}$ Mean of four measurements.

bynthetic mixture mimics the commercially available Uniretic ${ }^{\circledR}$.

cSynthetic mixture mimics the commercially available Timolide ${ }^{\circledR}$. 

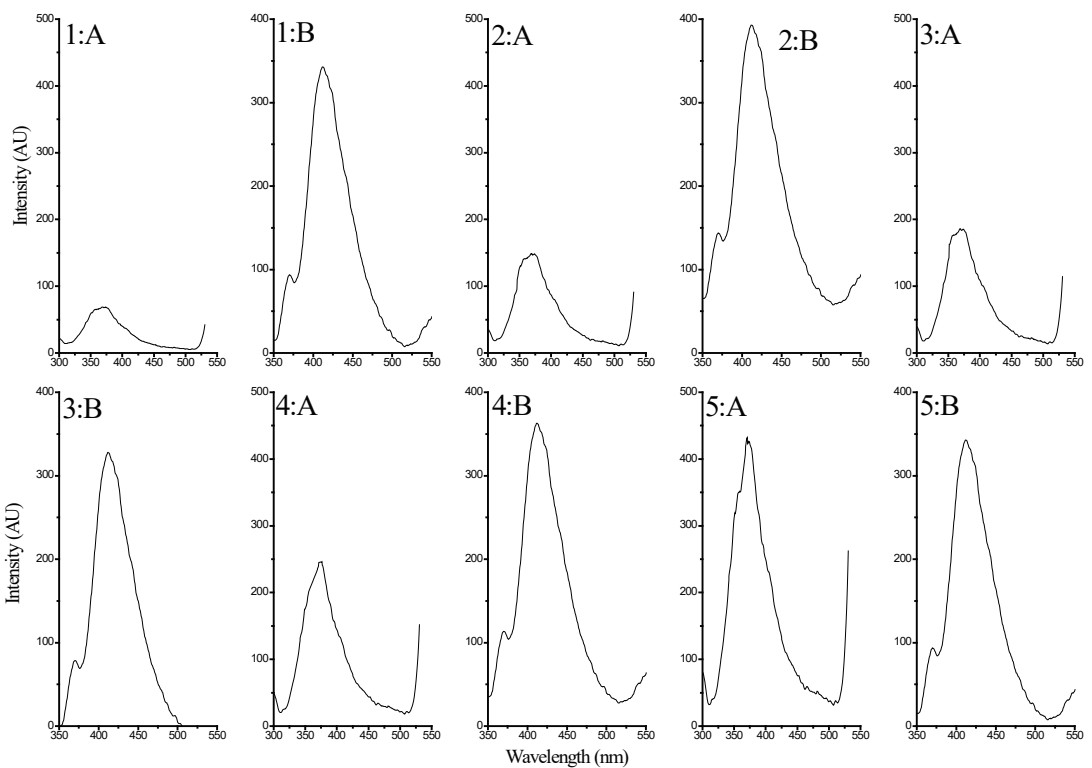

Fig. 3. Emission of synthetic mixtures 1, 2, 3, 4 and 5 from Table III. Each mixture has two emission spectra, A and B (A obtained using $\lambda_{\mathrm{ex}}=270 \mathrm{~nm}$, B obtained using $\lambda_{\mathrm{ex}}=330 \mathrm{~nm}$ ).
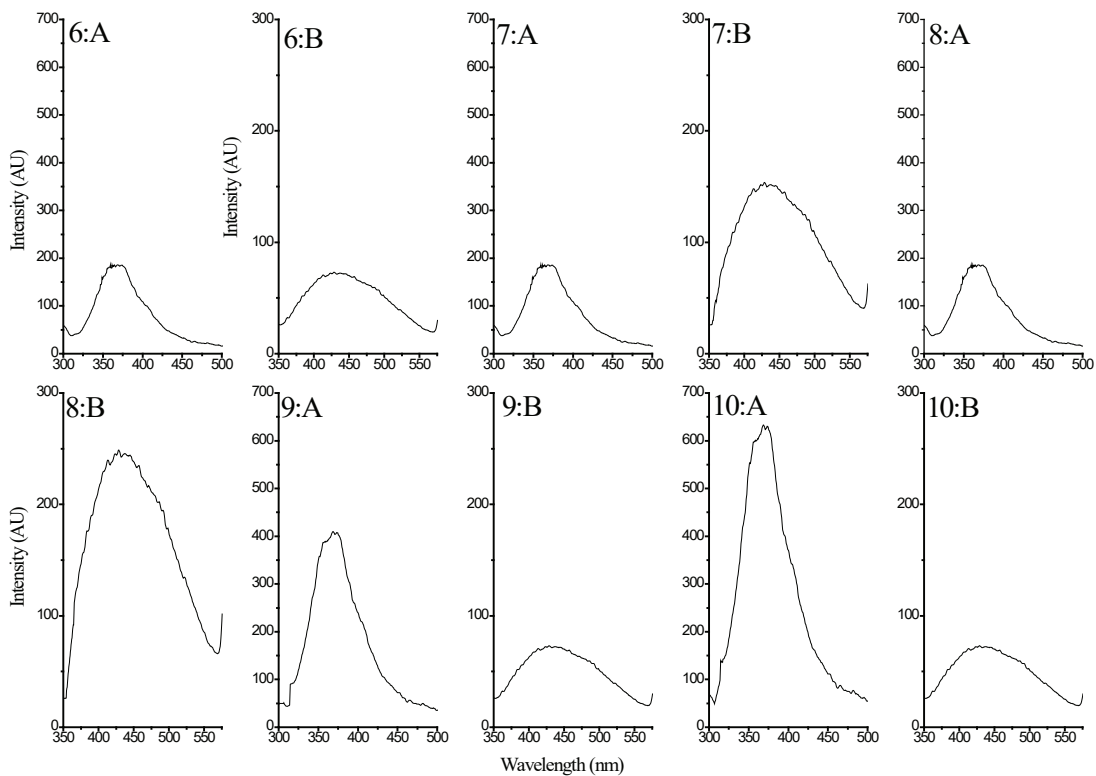

Fig. 4. Emission of synthetic mixtures 6, 7, 8, 9 and 10 from Table III. Each mixture has two emission spectra A and B (A obtained using $\lambda_{\mathrm{ex}}=270 \mathrm{~nm}$, B obtained using $\lambda_{\mathrm{ex}}=295 \mathrm{~nm}$ ). 
F. Wedian et al:: Simultaneous spectrofluorometric analysis of tablets containing hydrochlorothiazide combined with timolol maleate or amiloride hydrochloride, Acta Pharm. 70 (2020) 373-385.

Table IV. Results of robustness

\begin{tabular}{|c|c|c|c|}
\hline \multirow{2}{*}{ Parameter } & \multicolumn{3}{|c|}{ Recovery \pm RSD (\%) } \\
\hline & $\mathrm{HCT}^{\mathrm{a}}$ & $\mathrm{AMH}^{\mathrm{b}}$ & $\mathrm{TML}^{\mathrm{c}}$ \\
\hline \multicolumn{4}{|c|}{ Temperature $\left( \pm 5^{\circ} \mathrm{C}\right)^{\mathrm{d}}$} \\
\hline 17 & $100.2 \pm 1.3$ & $100.1 \pm 0.87$ & $99.8 \pm 1.4$ \\
\hline 27 & $98.8 \pm 1.6$ & $97.9 \pm 1.8$ & $97.8 \pm 1.8$ \\
\hline \multicolumn{4}{|c|}{ Excitation wavelength $( \pm 2 \mathrm{~nm})$} \\
\hline \multicolumn{4}{|l|}{268} \\
\hline \multicolumn{4}{|l|}{272} \\
\hline 293 & $101.1 \pm 0.31$ & & $99.6 \pm 0.35$ \\
\hline 297 & $100.6 \pm 0.59$ & & $99.8 \pm 0.67$ \\
\hline 328 & & $100.3 \pm 0.24$ & \\
\hline 332 & & $99.9 \pm 0.30$ & \\
\hline \multicolumn{4}{|c|}{ Emission wavelength $( \pm 2 \mathrm{~nm})$} \\
\hline \multicolumn{4}{|l|}{373} \\
\hline \multicolumn{4}{|l|}{377} \\
\hline 413 & $99.3 \pm 0.78$ & & \\
\hline 417 & $99.9 \pm 0.97$ & $100.0 \pm 0.87$ & \\
\hline 433 & & $101.2 \pm 0.76$ & $99.9 \pm 1.5$ \\
\hline 437 & & & $100.4 \pm 1.2$ \\
\hline
\end{tabular}

${ }^{a} \mathrm{HCT}(n=5)$, three concentrations $\left(5,7,11 \mathrm{mg} \mathrm{L}^{-1}\right)$, excitation and emission were 270 and $375 \mathrm{~nm}$, resp.

${ }^{\mathrm{b}} \mathrm{AMH}(n=5)$, three concentrations $\left(0.030,0.12,0.18 \mathrm{mg} \mathrm{L}^{-1}\right)$, excitation and emission were 330 and $415 \mathrm{~nm}$, resp.

c TML $(n=5)$, three concentrations $\left(6,16,24 \mathrm{mg} \mathrm{L}^{-1}\right)$, excitation and emission were 295 and $435 \mathrm{~nm}$, resp.

$\mathrm{d}$ The ambient temperature was $22^{\circ} \mathrm{C}$.

background for the emission spectra of HCT/AMH mixture solution to extract emission of the other component (mixture 1: A and B, resp., Fig. 3).

The analysis of the synthetic mixtures showed acceptable mean recoveries of $97.8 \pm 1.6$, $98.5 \pm 0.5$ and $97.1 \pm 1.0 \%$ for HCT, AMH and TML, resp. Moreover, the specificity was also evaluated regarding possible spectral interferences from the excipients. The emission spectra of commercial tablets solutions did not show any additional peaks when compared to the emission of synthetic mixtures. The concentration of each individual component in the synthetic mixtures was calculated from the regression equation of the calibration curve (see Table III).

Robustness. - The solutions were solely prepared in water. The $\mathrm{pH}$ of the spiked solutions (standards and mixtures) was above 7, the solution acidity was not modified at any condition to ensure the integrity of the active ingredients. Changing the solution composition by adding organic solvent or inorganic salts was completely excluded to ensure method greenness.

Small changes to the method conditions, including temperature, and excitation and emission wavelength, did not affect the recovery of the drugs. Recoveries ranged $97.8-101.6 \%$ and RSDs were 0.2-1.8\%, which indicated that the method was robust enough (see Table IV). 
F. Wedian et al.: Simultaneous spectrofluorometric analysis of tablets containing hydrochlorothiazide combined with timolol maleate or amiloride hydrochloride, Acta Pharm. 70 (2020) 373-385.

Table V. Determinations of HCT, AMT, TML in pharmaceutical preparations by proposed and literature methods

\begin{tabular}{lcccc}
\hline & \multicolumn{2}{c}{ Proposed method } & \multicolumn{2}{c}{${\text { Literature } \text { method }^{\mathrm{a}}}$} \\
\cline { 2 - 5 } & AMH & HCT & AMH & HCT \\
\hline Uniretic $^{\circledR}$ & & & & \\
$(50 \mathrm{mg} \mathrm{AMH}+5 \mathrm{mg} \mathrm{HCT})$ & & & & \\
${\text { Found }(\mathrm{mg})^{\mathrm{b}}}$ & $47.87 \pm 0.88$ & $4.52 \pm 0.47$ & $48.90 \pm 0.91$ & $4.60 \pm 0.90$ \\
$t(2.23)^{\mathrm{c}}$ & 1.99 & 0.193 & & \\
$F(5.05)^{\mathrm{c}}$ & 1.07 & 3.67 & & HCT \\
& TML & HCT & TML & \\
Timolide $^{\circledR}$ & & & & \\
$(25$ mg TML $+10 \mathrm{mg} \mathrm{HCT})$ & & & & \\
${\text { Found }(\mathrm{mg})^{\mathrm{b}}}$ & $23.52 \pm 0.36$ & $9.74 \pm 0.14$ & $23.71 \pm 0.19$ & \\
$t(2.23)^{\mathrm{c}}$ & 1.14 & 0.467 & & \\
$F(5.05)^{\mathrm{c}}$ & 3.59 & 3.08 & & \\
\hline
\end{tabular}

${ }^{\mathrm{a}}$ Chromatographic method using reversed-phase column (ref. 23); ${ }^{\mathrm{b}} \mathrm{Mean} \pm \mathrm{SD}, n=6 ;{ }^{\mathrm{c}}$ Tabulated $t$ - and $F$-values at $p=0.05$.

Table VI. Selected published detection limits of HCT, TML and AMH

\begin{tabular}{lcccc}
\hline & \multicolumn{1}{c}{ Method } & Detection & $\begin{array}{c}\text { Detection limit } \\
\left(\mathrm{mg} \mathrm{L}^{-1}\right)\end{array}$ & Ref. \\
\hline HCT & Chromatography $^{\mathrm{a}}$ & $\mathrm{UV}$ & 0.22 & 18 \\
& Spectrophotometry $^{\mathrm{b}}$ & $\mathrm{UV}$ & 0.32 & 18 \\
& Spectrofluorometry $^{*}$ AMH & Fluorescence & 0.0104 & This work \\
& Chromatography $^{\mathrm{c}}$ & $\mathrm{UV}$ & 0.381 & 19 \\
& Spectrophotometry $^{\mathrm{d}}$ & $\mathrm{UV}$ & 0.25 & 20 \\
\multirow{3}{*}{ TML } & Spectrofluorometry $^{*}$ & Fluorescence & 0.0013 & This work \\
& Chromatography $^{\mathrm{e}}$ & $\mathrm{UV}$ & 0.21 & 21 \\
& Spectrophotometry $^{\mathrm{f}}$ & $\mathrm{UV}$ & 0.64 & 22 \\
& Spectrofluorometry $^{*}$ & Fluorescence & 0.070 & This work \\
\hline
\end{tabular}

${ }^{a} \mathrm{RPC}_{18}$ base deactivated silica column with a mobile phase consisting of triethylamine ( $\left.\mathrm{pH} 3.0\right)$ adjusted with orthophosphoric acid and acetonitrile, the flow rate of $1.4 \mathrm{~mL} \mathrm{~min}^{-1}$; ${ }^{\mathrm{b}}$ Generation of ratio spectra of two-drug combinations, candesartan cilexetil and HCT. HCT was estimated using the amplitudes between 251 and $276 \mathrm{~nm}$; ${ }^{\mathrm{R}} \mathrm{RP}-\mathrm{HPLC}$ using a Shim-pack $\mathrm{C}_{18}$ column at a flow rate of $1 \mathrm{~mL} \mathrm{~min}^{-1}$. The mobile phase consisted of water and acetonitrile in the ratio of 35:65, using a UV detector at $281 \mathrm{~nm}$; ${ }^{\mathrm{d}}$ Sorption of amiloride on a cation-exchange resin at $\mathrm{pH} 4.0$ and direct

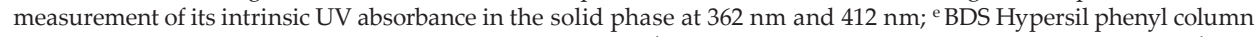
and a mobile phase consisting of acetonitrile and $25 \mathrm{mmol} \mathrm{L}^{-1}$ phosphate buffer, $\mathrm{pH} 4.0(50: 50, V / V), 1.2 \mathrm{~mL} \mathrm{~min}^{-1}$, UV detection at $210 \mathrm{~nm} ;{ }^{\mathrm{f}}$ Derivative spectrophotometry using the zero-crossing measurements. Linear calibration graphs of first-derivative values at $250.3 \mathrm{~nm}$ for dorzolamide hydrochloride and $315.8 \mathrm{~nm}$ for TML. 


\section{Analysis of commercial formulations}

The proposed methods were applied to the analysis of two commercially available drug formulations, Uniretic ${ }^{\circledR}$ and Timolide ${ }^{\circledR}$. The background subtraction method was applied to determine the concentration of each individual compound in those formulations. The recovered amount of drugs from tablets was in a good agreement with claimed values (Table V). The amount of AMH and HCT found in Uniretic ${ }^{\circledR}$, expressed in mg per tablet, was $47.87 \pm 0.88$ for AMH and $4.52 \pm 0.47$ for HCT with label compliance ( \pm SD) of $95.6 \pm 0.7$ and $90.2 \pm 0.4 \%$, resp., while the amount of TML and HCT in Timolide ${ }^{\circledR}$ was 23.52 \pm 0.36 and $9.74 \pm 0.41 \mathrm{mg}$, giving a label compliance of $94.1 \pm 0.2$ and $97.4 \pm 0.7 \%$ for TML and HCT, resp.

Statistical analysis of the results obtained by the proposed method versus the HPLC method (23) showed no significant differences in performance at $p=0.05$ as indicated by the Student's $t$-test and variance $F$-test for AMH/HCT and TML/HCT drug combinations (Table V). This indicates that the proposed method is applicable to quantitative analyses.

Comparison of detection limits of this work and previously published values for HCT, $\mathrm{AMH}$ and TML is listed in Table VI.

\section{CONCLUSIONS}

Spectrofluorometric methods for the quantitative analysis of HCT, AMH and TML in combined pharmaceutical formulations were evaluated. The methods have many advantages such as simplicity, rapidity, selectivity and reasonable sensitivity. They offer low-cost analyses, using chemicals and equipment available in any analytical laboratory. The method for HCT/AMH and HCT/TML analysis was found reliable for routine applications. Further studies on other drug combinations are under the way.

Acknowledgements. - The authors would like to thank Prof. Dr. Yaser AlHaj for his contribution to the discussion. The authors would also like to thank the Yarmouk University - Faculty of Graduate Studies and Scientific Research for financial support.

\section{REFERENCES}

1. M. C. F. Ferraro, P. M. Castellano and T. S. Kaufman, Simultaneous determination of amiloride hydrochloride and hydrochlorothiazide in synthetic samples and pharmaceutical formulations by multivariate analysis of spectrophotometric data, J. Pharm. Biomed. Anal. 30 (2002) 1121-1131; https://doi.org/10.1016/s0731-7085(02)00420-x

2. B. G. Katzung, S. B Masters and A. J. Trevor, Basic and Clinical Pharmacology, $13^{\text {th }}$ ed, McGraw-Hill, New York 2012.

3. D. J. Mazzo, Analytical Profile of Drug Substances, Academic Press, London 1986, Vol. 15, pp. 1-34.

4. M. Kartal and N. Erk, Simultaneous determination of hydrochlorothiazide and amiloride hydrochloride by ratio spectra derivative spectrophotometry and high-performance liquid chromatography, J. Pharm. Biomed. Anal. 19 (1999) 477-485; https://doi.org/10.1016/s0731-7085(98)00241-6

5. J. Rouland, P. Morel-Mandrino, P. Elena, H. Polzer and P. Sunder Raj, Timolol 0.1\% gel (Nyogel $0.1 \%{ }^{\circledR}$ ) once daily versus conventional timolol $0.5 \%$ solution twice daily: A comparison of efficacy and safety, Ophthalmologica 216 (2002) 449-454; https://doi.org/10.1159/000067548 
6. N. Erk and F. Onur, Three new spectrophotometric methods for simultaneous determination of hydrochlorothiazide and amiloride hydrochloride in sugar-coated tablets, Anal. Lett. 30 (1997) 1503-1515; https://doi.org/10.1080/00032719708001671

7. C. V. N. Prasad, C. Parihar, K. Sunil and P. Parimoo, Simultaneous determination of amiloride $\mathrm{HCl}$, hydrochlorothiazide and atenolol in combined formulations by derivative spectroscopy, J. Pharm. Biomed. Anal. 17 (1998) 877-884; https://doi.org/10.1016/s0731-7085(97)00241-0

8. M. H. Abdel-Hay, A. A. Gazy, E. M. Hassan and T. S. Belal, Derivative and derivative ratio spectrophotometric analysis of antihypertensive ternary mixture of amiloride hydrochloride, hydrochlorothiazide and timolol maleate, J. Chin. Chem. Soc. 55 (2008) 971-978; https://doi.org/10.1002/ jccs.200800144

9. M. E. Martín, O. M. Hernández, A. I. Jiménez, J. J. Arias and F. Jiménez, Partial least-squares method in analysis by differential pulse polarography. Simultaneous determination of amiloride and hydrochlorothiazide in pharmaceutical preparations, Anal. Chim. Acta 381 (1999) 247-256; https://doi.org/10.1016/s0003-2670(98)00732-6

10. M. Zecevic, L. J. Zivanovic, S. Agatonovic-Kustrin, D. Ivanovic and M. Maksimovic, Statistical optimization of a reversed-phase liquid chromatographic method for the analysis of amiloride and hydrochlorothiazide in tablets, J. Pharm. Biomed. Anal. 22 (2000) 1-6; https://doi.org/10.1016/ s0731-7085(99)00253-8

11. M. C. F. Ferraro, P. M. Castellano and T. S. Kaufman, Chemometric determination of amiloride hydrochloride, atenolol, hydrochlorothiazide and timolol maleate in synthetic mixtures and pharmaceutical formulations, J. Pharm. Biomed. Anal. 34 (2004) 304-314; https://doi.org/10.1016/ s0731-7085(03)00521-1

12. A. A. Elshanawane, L. M. Abdelaziz, M. S. Mohram and H. M. Hafez, Development and validation of HPLC method for simultaneous estimation of brimonidine tartrate and timolol maleate in bulk and pharmaceutical dosage form, J. Chromatogr. Sep. Tech. 5 (2014) Article ID 1000230 (5 pages); https://doi.org/10.4172/2157-7064.1000230

13. F. P. Bigley, R. L. Grob and G. S. Brenner, Pharmaceutical applications of a high-performance flow injection system, Anal. Chim. Acta 181 (1986) 241-244; https://doi.org/10.1016/s0003-2670(00)85240-x

14. M. Kaljurand and M. Koel, Recent advancements on greening analytical separation, Crit. Rev. Anal. Chem. 41 (2011) 2-20; https://doi.org/10.1080/10408347.2011.539420

15. International Conference in Harmonization of Technical Requirements for Registration of Pharmaceuticals for Human Use, ICH Harmonised Tripartite Guideline, Validation of Analytical Procedures: Text and Methodology Q2(R1), Current Step 4 version, ICH, November 2005; http://www.ich.org/ fileadmin/Public_Web_Site/ICH_Products/Guidelines/Quality/Q2_R1/Step4/Q2_R1_Guideline. pdf; last access: June 2018

16. S. J. Kok, R. Evertsen, N. H. Velthorst, U. A. Th. Brinkman and C. Gooijer, On the coupling of fluorescence line-narrowing spectroscopy and poly(ethylene thin-layer chromatography)iminecellulose, Anal. Chim. Acta 405 (2001) 1-7; https://doi.org/10.1016/S0003-2670(99)00698-4

17. A. K. Aimukhanov and N. Kh. Ibrayev, Influence of overlapping between the fluorescence spectra of dye molecules and the spectrum of plasmon absorption of silver nanoparticles on the luminescence of laser dyes in ethyl alcohol, Eurasian J. Phys. Func. Mat. 2 (2018) 43-53; https://doi. org/10.29317/ejpfm.2018020105

18. V. S. Bhadresh, H. A. Raj, S. Rajanit and S. Harshita, Analytical techniques for determination of hydrochlorothiazide and its combinations: A review, Int. J. Adv. Sci. Res. 1 (2015) 114-128; https:// doi.org/10.7439/ijasr

19. J. S. Shaikh and N. N. Rao, Simultaneous estimation and forced degradation studies of amiloride hydrochloride and furosemide in a pharmaceutical dosage form using reverse-phase high-performance liquid chromatography method, Asian J. Pharm. Clin. Res. 11 (2018) 215-221; https://doi. org/10.22159/ajpcr.2018.v11i7.25783 
20. P. Ortega-Barrales, G. Pellerano, F. A. Vazquez and A. Molina-Díaz, Rapid and sensitive determination of amiloride by cation exchange preconcentration and direct solid-phase UV detection, Anal. Lett. 35 (2002) 1491-1504; https://doi.org/10.1081/AL-120006725

21. M. Walash and R. El-Shaheny, Fast separation and quantification of three anti-glaucoma drugs by high-performance liquid chromatography UV detection, J. Food Drug Anal. 24 (2016) 441-449; https://doi.org/10.1016/j.jfda.2015.11.006

22. N. Erk, Simultaneous determination of dorzolamide $\mathrm{HCl}$ and timolol maleate in eye drops by two different spectroscopic methods, J. Pharm. Biomed. Anal. 15 (2002) 391-397; https://doi.org/10.1016/ S0731-7085(01)00627-6

23. S. Mahgoub, Novel stability-indicating RP-HPLC method for determination of hydrochlorothiazide, amiloride hydrochloride and timolol maleate in tablet dosage form, Am. J. Mod. Chromatogr. 3 (2016) 23-32; https://doi.org/10.7726/ajmc.2016.1002 